\title{
Going Green is Good for You: Why We Need to Change the Way We Think About Pro-Environmental Behaviour
}

\author{
Michael Prinzing \\ ORCID: 0000-0002-7879-7131 \\ michael@prinzing.net
}

\begin{abstract}
Awareness and concern about climate change are widespread. But rates of pro-environmental behaviour are low. This is partly due to the way in which pro-environmental behaviour is framed-as a sacrifice or burden that individuals bear for the planet and future generations. This framing elicits wellknown cognitive biases, discouraging what we should be encouraging. We should abandon the self-sacrifice framing, and instead frame pro-environmental behaviour as intrinsically desirable. There is a large body of evidence that, around the world, people who are living more environmentally lifestyles are happier than those not doing so. This is the message we should be spreading.
\end{abstract}

Keywords: climate change; consumer behaviour; happiness; subjective wellbeing

Published in Ethics, Policy and Environment: https://doi.org/10.1080/21550085.2020.1848192 


\section{Introduction}

Developed countries consume an incredible share of the world's resources and are consequently responsible for the majority of global carbon emissions. North America, for instance, which makes up $5 \%$ of the global population produces $18 \%$ of global emissions (Ritchie, 2018). Roughly a third of emissions in rich countries are attributable directly to individual consumption (Vandenbergh et al., 2010). But, when indirect energy consumption is taken into account, household behaviour is the largest contributor to total energy use and carbon emissions in most developed countries (Hertwich, 2005; Hertwich \& Peters, 2009). Thus, lifestyle changes in rich countries_-particularly amongst their wealthier members-would make an enormous difference in ameliorating climate change (Dietz et al., 2009; Gardener \& Stern, 2009; IPCC, 2007).

Unfortunately, current strategies for encouraging lifestyle change aren't working. The data show that people are increasingly convinced of, and concerned about, anthropogenic climate change- $70 \%$ of Americans think climate change is happening (only 14\% think it's not); $58 \%$ believe that it is human-caused; $62 \%$ are worried; and $63 \%$ say that it is personally important to them (Leiserowitz et al., 2018). However, few meaningful changes have been made to actual behaviour (National Geographic, 2014). Information campaigns consistently result in scant differences (Steg \& Vlek, 2009, p. 313). And, though stronger environmental values do predict more pro-environmental behaviour $(\mathrm{PEB})^{1}$, this relationship is often weak (Gifford \& Nilsson,

${ }^{1} \mathrm{I}$ intend this to be a fairly broad category of actions that help a person to reduce or to maintain low levels of resource consumption and greenhouse gas emissions-e.g., recycling, buying used rather than new products, bicycling rather than driving, etc. 
2014). In other words, there is a value-action gap. Even those who accept the scientific consensus and care about the future of the planet are motivationally deficient. I argue that this is partly because the way in which people, including environmentalists, typically think and talk about PEB actually discourages PEB. There are arguably a number of problems. But the one I focus on here is the 'self-sacrifice framing', according to which going green is a personal sacrifice or burden for the collective good. This paper argues that we should reframe PEB as intrinsically appealing, rather than a loss one must suffer to avert a distant disaster.

\section{The importance of framing}

The pioneering work of Amos Tversky, Daniel Kahneman and their colleagues made famous the ways in which framing can affect behaviour (Kahneman, 2011; Kahneman et al., 1991; Tversky \& Kahneman, 1981). The basic idea is that the way in which we conceptualize something — such as a challenge like climate change — has a big effect on how we respond to it. Notice that I just called climate change a 'challenge'-rather than a 'problem'. That's an example of a difference in framing.

\subsection{The problem of psychological distance}

The importance of framing in climate change communication has previously been recognized in the context of what I'll call the psychological distance problem (Lindenberg \& Steg, 2007; Morton et al., 2011; Moser \& Dilling, 2011). 'Psychological distance' is the extent to which an object of thought feels far away from the self, or the here and now (Liberman et al., 
2007). ${ }^{2}$ According to Construal Level Theory (Trope \& Liberman, 2010), as psychological distance increases, construals (i.e., how things are perceived and thought about) become increasingly abstract. When people experience something directly, their cognitive representations of that thing tend to be concrete and detailed. When the object of thought is very psychologically distant, representations tend to be vague and abstract. Since the vividness with which an outcome can be imagined affects its weight in decision-making (Kahneman, 2011, pp. 326-328; Rottenstreich \& Hsee, 2001), psychologically distant outcomes receive less weight in deliberation.

Psychological distance can be created by perceptions of spatial, temporal, or social distance, as well as degree of uncertainty or hypotheticality (Trope \& Liberman, 2010). For most people living in rich countries, the effects of climate change are distant in each of these ways. While some pernicious effects are already being felt in many places around the world, the most serious consequences will not arrive for years. This can be a problem because of the human tendency to engage in future discounting (Ainslie, 2001). People tend to prefer small gains now to larger gains in the future in predictably irrational ways. Moreover, many of the wealthy people whose lifestyles have the biggest impacts live in places that are not yet suffering from very serious problems. The physical proximity of environmental degradation is a strong predictor of

${ }^{2}$ There are some definitional difficulties here. For instance, one dimension of psychological distance is social distance (Liberman et al., 2007). Yet, while people clearly do feel "closer" to some than others, it's unclear how this kind of distance is related to spatial or temporal distance. For present purposes, however, we needn't delve into these complexities. (My thanks to an anonymous reviewer for bringing this to my attention.) 
pro-environmental motivation (Scannell \& Gifford, 2013). People respond more strongly when they feel that their own local environment is threatened. Because geographic distance entails cultural difference, there will also be significant social distance between heavy emitters and the people who will suffer the worst consequences of climate change (e.g., those living in small island communities). Another source of psychological distance comes from the fact that climate change is large in scale, difficult to understand, and uncertain in its effects. Most laypeople don't know the scientific evidence themselves, and must rely on experts (or putative experts) to summarize the evidence and its implications. This introduces greater uncertainty, particularly given the existence of high-profile climate change deniers.

Between these factors, the effects of climate change are very psychologically distant (Spence et al., 2012; Wang et al., 2019). This means that people are not highly motivated to adopt ameliorative responses. Since we have trouble imagining with any clarity or vividness how the global climate will change, whom will be affected, in what way, etc., our response to the problem is not as robust as it should be.

The solution, others have suggested, is to reframe climate change messages-i.e., change the way that we think and talk about it (Newell et al., 2014; Newell \& Pitman, 2010). It's generally thought that we can motivate stronger responses to climate change by reducing the psychological distance: framing it as happening sooner, nearer, to people like you, and with more certainty. There is experimental evidence that this can indeed result in stronger proenvironmental attitudes and behaviour (Jones et al., 2017; Lee et al., 2018; Pahl \& Bauer, 2013; Soliman et al., 2018). However, it can also do the opposite (McDonald et al., 2015). This may be partly because such framings can evoke fear or distress. Fear-inducing messages can 'distance or disengage individuals from climate change, tending to render them feeling helpless and 
overwhelmed', thereby reducing PEB (O’Neill \& Nicholson-Cole, 2009, p. 375). It's also been found that dire-sounding messages ('The end is near!') can reduce confidence in the reality climate change-perhaps by conflicting with implicit 'just world' beliefs (Feinberg \& Willer, 2011). Environmentalists using distance-reducing frames can be seen as sensationalizing, or even manipulating people into responding in ways that they wouldn't consider warranted if the problem were presented differently. Thus, while distance-reducing frames may be beneficial in some cases, their usefulness is limited.

\subsection{The self-sacrifice framing}

The psychological distance problem is a problem with how climate change itself is framed. Problems with how $P E B$ is framed are less frequently discussed. But they are at least as important. Here, I focus on what I call the 'self-sacrifice framing', on which PEBs are seen as personal sacrifices - bad for the person performing them (compared with less environmentally friendly alternatives) but good for the planet and/or other people, including future generations. In both academic writing and the popular press, a green lifestyle 'is usually portrayed as an onerous undertaking, one requiring personal sacrifice of the highest order. People... are being asked to give up a modern, high-technology existence for an austere, bleak but needed substitute' (De Young, 1990, p. 216). ${ }^{3}$ As one commentator writes:

${ }^{3}$ John Broome (2012) has offered what he calls a 'sacrifice-free' solution to climate change. I take no stand on the merits of his argument. But it's worth mentioning because the fact that his argument is so-called, and so controversial (e.g., Lawlor, 2016) reveals how deeply the notion of sacrifice is entrenched in our ways of thinking and talking about PEB. Some researchers have suggested that not all PEBs involve sacrifices; some can be 'win-wins'-i.e., good for the planet 
Environmentalism has long preached sacrifice. Since its inception, it has counseled a type of restraint that requires foregoing certain immediate pleasures for the higher goal of ecological well-being. Environmentalism tells us... [to] hold ourselves back... in the interest of environmental protection. (Wapner, 2010, p. 33)

According to this received wisdom, an environmentally friendly lifestyle is not something that people like or that would be good for them, so much as something they have no choice but to accept. After all, people want to keep getting bigger houses, faster cars, and newer phones. But since that's not sustainable, they must settle for less. They will be made worse off by their new, austere lifestyle. Their fun will be over. But that's the sacrifice they have to make for the future of our planet and our species.

The so-called "techno-optimists" argue that these sacrifices will not actually be necessary; novel technologies will enable people to live high-consumption lifestyles without negatively impacting the climate (Shellenberger \& Nordhaus, 2011). Others respond that it this optimism is unjustified, and we cannot take such a dangerous gamble (Agar, 2016; Alexander, 2014). Yet both parties to this debate presuppose that environmentally friendly lifestyles would constitute sacrifices. The disputed question is whether these sacrifices are necessary.

This self-sacrifice framing naturally leads people to understand climate change as a collective action problem. In fact, this seems to be the default assumption, not just in popular perceptions, but in academic research (Bilandzic et al., 2017; Gardiner, 2006; Newell et al.,

and for individuals (Dietz et al., 2009). But, again, the fact that they claim to have found a few win-wins reveals that they think most PEBs are win-loses (i.e., sacrifices). 
2014; Steg et al., 2014; Steg \& Vlek, 2009). The idea is that, 'collectively, we are better off if the environment is protected, but rational self-interest often dictates environmental exploitation' (Karp, 1996, p. 111). The dangers of environmental catastrophe are enormous. But, since each individual is better off not going green, and will almost certainly not (by themselves) tip the balance, it's in each person's interest to free ride. While we each want others to go green, we don't want to do so ourselves. In fact, climate change can seem like the ultimate bystander scenario. 'The bystander effect' refers to the fact that individual motivation to do something about a problem is inversely related to the number of people who could do something about it (Peter et al., 1972). Just about every person one knows could contribute comparably to ameliorating climate change. Hence, we're all bystanders.

For those actually trying to encourage people to go green, the self-sacrifice framing is highly counterproductive. If one wants people to do something, the last thing one should do is frame that behaviour as a sacrifice. Human decision-making is loss-averse, and subject to the 'endowment effect' (Kahneman et al., 1991). That is, people treat losses as more important than equivalent gains (Baumeister, 2001), and value what they have more highly because it's theirs. This means that people are very resistant to letting go of what they have become accustomed to. Indeed, many of the things that people are asked to change are important parts of their social identities. (For many rural American men, for instance, driving a big truck is a constituent of their sense of self and masculinity.) Studies have found that one of the strongest predictors of willingness to engage in PEB and support environmentalist public policies is the size of the perceived personal costs (Tobler et al., 2012). If PEB is framed as involving personal costs in the name of collective benefits, people will tend to see PEB as a (onerous) social or moral obligation, rather than something attractive for its own sake. This is discouraging since people 
are often more motivated to pursue ideals than they are to live up to obligations (Does et al., 2011). Of course, people frequently do make personal sacrifices for the good of others, and live up to their perceived obligations. We are altruistically as well as prudentially motivated. The point is just that the self-sacrifice framing discourages what we should be encouraging.

Environmentalists looking to persuade large numbers of people to modify their lifestyles need a new rhetorical strategy_one that bypasses the problems associated with psychological distance as well as loss aversion and the endowment effect. As things stand, the perceived costs of profligate consumption are psychologically distant (and so motivationally anaemic), and the perceived benefits are immediate and personal (and so motivationally robust). This is a deadly combination. People will be averse to suffering the perceived costs. And they will lack a clear sense of payoff - indeed they are likely to doubt that there will be any payoff, for themselves at any rate.

\section{How self-interest can power green lifestyle change}

There has been growing interest, in recent years, in the 'co-benefits' of PEB and public policies (Bain et al., 2016; Elliott, 2014; Walker et al., 2018). A co-benefit is a positive, nonenvironmental outcome of pro-environmental actions (whether collective or individual). For instance, many PEBs and green policies benefit human health (Thurston, 2013; West et al., 2013). Reduced pollution improves air quality, and more environmentally friendly modes of transportation (e.g., walking, bicycling) involve increased exercise. It's been found that emphasizing the co-benefits of pro-environmental action increases pro-environmental values and motivation (Maibach et al., 2010).

One particularly important reason to adopt co-benefit framings is that they can appeal to broad audiences. The topic of climate change is heavily politicized - a part of the "culture wars" 
(Bliuc et al., 2015; Hornsey et al., 2016). Efforts to educate climate change deniers are often futile (Hoffman, 2011; Whitmarsh, 2011). It's been remarked that the odds of changing a climate change denier's mind are about as high as the odds of changing a conservative Christian's mind on abortion (Bain et al., 2012, p. 600). Politically charged beliefs are influenced primarily by emotions, group membership, and worldview (Haidt, 2012; Kahan, 2010; Lewandowsky \& Oberauer, 2016) — not an impartial consideration of evidence. However, even climate change deniers can be brought to favour PEBs and policies with the right framing (Bain et al., 2016). One proven strategy is to emphasize how PEBs and environmentalist policies can lead to greater societal flourishing and economic or technological development (Bain et al., 2012). And there is no correlation between political affiliation and attitudes towards PEBs perceived as involving small personal costs and large environmental benefits (Tobler et al., 2012). In other words, if you want deniers to go green, don't try to convince them of the reality of anthropogenic climate change. Instead, convince them that — for reasons independent of the environment — behaviours and policies that happen to be green are independently good. ${ }^{4}$

${ }^{4}$ There is some debate as to whether it's more effective to combine co-benefit and environmental frames, or to appeal solely to co-benefits (Elliott, 2014). It seems clear that this will depend on the audience. For those convinced of anthropogenic climate change, the combined appeal will probably be better. Two reasons are greater than one. For climate change deniers, however, the environmental appeal will be, at best, a distraction. For them, it will probably be more effective to appeal solely to the co-benefits (Bain et al., 2012). Designing audience-specific messages is an interesting avenue for further empirical research. 
One seldom discussed co-benefit of PEB is individual well-being. The vast majority of people — regardless of whatever else they care about—are strongly motivated by their own good. It would be immensely effective, then, if we could convince people that-far from being a sacrifice - going green is actually good for them (De Young, 2000; Jackson, 2008). In this way, individual self-interest could be directed towards the promotion of the common good. Reframing PEB as good for personal well-being would simultaneously eliminate multiple barriers to ameliorating climate change. It would make (at least some of) the perceived costs of green lifestyles disappear, thus avoiding loss aversion and the endowment effect. It would also allow us to dodge the psychological distance problem, as the reasons to engage in PEB would no longer have to do with averting some distant disaster. Thankfully, promoting this belief would not involve any deception or bad faith. (I take no stand here on whether it would be justified to promote this message if it weren't true.) It may come as a surprise to many, but there is strong evidence that green lifestyles do not generally make people less happy. Quite the opposite, PEB comes with greater happiness and well-being. Thus, we should abandon the rhetoric of personal sacrifice because, in addition to being counterproductive, it's not even true.

Before surveying the evidence for this claim, I should mention some qualifications. First, even those highly motivated to adopt a green lifestyle will face obstacles and barriers. People don't always do what they believe is best for themselves. Think of how difficult it can be for some people to eat a healthy diet—even though they know that it's in their interest to do so. Old habits can make change difficult (Klöckner, 2013). There are also situational factors that can block or discourage PEB (e.g., a lack of public transport). Second, my proposed reframing is meant as a supplement to, not substitute for, public policy. Public incentives for PEBs should still be encouraged, and pro-environmental 'nudges' are highly advisable (Sunstein \& Thaler, 
2008). ${ }^{5}$ So, in short, I'm not claiming that busting the sacrifice myth would leave nothing standing in the way of pro-environmental lifestyle change. The claim is that it would be a very useful step in the right direction.

\section{Environmentalism and subjective well-being}

'Subjective well-being' (SWB) refers to the psychological components of human flourishing (Diener, 2012; Diener et al., 2002). It encompasses a range of psychological constructs, including: positive emotional states, life satisfaction, and feelings of social connection, meaningfulness, and purpose. ${ }^{6}$ There is a great deal of evidence for a positive relationship between SWB and environmentalism. As Tim Kasser wrote in a recent review, 'findings from 13 different studies spanning several nations and tens of thousands of subjects

reveal a consistent significant positive correlation between $[\mathrm{SWB}]$ and their engagement in [PEBs]' (2017, p. 3). In this section, I'll review some highlights of recent research and explore some theoretical explanations for the findings.

${ }^{5}$ People incentivized to engage in certain PEBs (like using public transport rather than driving) will sometimes persist in those behaviours even after the incentives are removed (Fujii \& Kitamura, 2003), suggesting that they have realized the PEB is not a (significant) sacrifice. Incentives programs could thus be used to kick-start green habits, without needing to continue for long periods, thereby ringing up large taxpayer bills.

${ }^{6}$ For convenience, I sometimes use 'happiness' in place of 'SWB'. I mean them to be synonymous. 
One of the earliest studies, conducted by Kirk Brown and Tim Kasser (2005), aimed explicitly to see whether individual and ecological well-being are compatible. The authors summarize their findings thus:

In a sample of adolescents and again in matched, demographically diverse national samples of adults differing in lifestyle... personal well-being and ecologically responsible behaviour were complementary. That is, happier people were living in more ecologically sustainable ways... These results weigh against the oft-stated belief that personal well-being and ecologically supportive behaviour are necessarily in conflict... (Brown \& Kasser 2005, 360)

These are correlational data. They don't show that going green causes people to become happier. But, as Brown and Kasser note, they do bust the myth that a green lifestyle is typically a personal sacrifice.

One might suspect that this relationship only holds for some small portion of the population. Perhaps it's just the wealthy, or the WEIRD (Henrich et al., 2010), for whom personal and planetary well-being are complementary. Or perhaps a green lifestyle is associated with happiness only when one already values the environment, or when one's peers generally consider PEBs virtuous. While there is some evidence that social norms can play a moderating role in the PEB-SWB relationship (Welsch \& Kühling, 2018), this suspicion is not supported by the data. Brown and Kasser's findings have been repeatedly replicated across cultures. A study using data from approximately 24,000 people around the world found a positive and significant 
relationship between PEB and SWB (Welsch \& Kühling, 2010). ${ }^{7}$ This relationship is significant even controlling for nationality, socioeconomic status, and differences in personal attitudes towards consumption. Numerous studies around the world have corroborated this finding (Corral-Verdugo et al., 2011; Jacob et al., 2009; Kaida \& Kaida, 2016; Welsch \& Kühling, 2011; Xiao \& Li, 2011). This shows that a green lifestyle is not associated with happiness only for the special few who are Western, rich, or who happen to care about the environment.

Another line of evidence comes from research on materialism (Kasser, 2002). Materialistic people are those who highly value money and material possessions, and who see these as indicators of success and social status (Richins \& Dawson, 1992). Unsurprisingly, materialism is a strong predictor of environmentally unfriendly attitudes and behaviours (Hurst et al., 2013). Of course, high levels of consumption are not identical with materialism (there are other reasons why one might have a large environmental footprint). But materialism is rampant in rich countries, and a major cause of over-consumption. Since reducing consumption generally

${ }^{7}$ In this study, life satisfaction correlated with engagement in PEB at $r=.21$. For comparison, the correlation between life satisfaction and household income was only $r=.17$. Kasser (2017) reports standardized regression coefficients for specific PEBs. These range from $\beta=.05$ (for, e.g., using recycling bins) to $\beta=.12$ (for, e.g., trading or sharing products rather than buying). The PEBs with the strongest relationships to SWB have been found to be those involving more personal effort, such as making things for oneself, and more social interactions, such as cohabitating (Schmitt et al., 2018). Self-determination theory (discussed below) may explain why this. 
has a far larger impact than stereotypical PEBs like recycling (Gardner \& Stern, 2002), materialists should be a primary target-audience for environmentalist campaigns.

Multiple meta-analyses, encompassing hundreds of studies, have found a strong and negative relationship between materialism and SWB (Dittmar et al., 2014; Wright \& Larsen, 1993). Materialistic people experience fewer positive emotions and more negative emotions, are less satisfied with their lives, and find their lives to be less meaningful. This finding is remarkably stable across demographics. Even business students, whose social circles one would expect to be supportive of materialism, are less happy when they are more materialistic (Kasser \& Ahuvia, 2002; Vansteenkiste et al., 2006). Higher levels of materialism even predict more physical ailments like headaches and faintness (Kasser \& Ryan, 1993). The relationship between materialism and reduced SWB appears to be causal. For instance, in one study, participants who were primed with materialistic cues (e.g., ads for luxury goods) scored higher on materialism and consequently higher on depression, anxiety and shame, than participants primed with control images (Bauer et al., 2012). Longitudinal studies (covering one half, two, and twelve years) have found that changes in a person's level of materialism lead to corresponding changes in SWB, and interventions that decrease materialism also help to improve SWB (Kasser et al., 2014).

This negative materialism-SWB relationship is mediated by several factors. First, much of the relationship is explained by changes in gratitude (Tsang et al., 2014). People who are less materialistic are more grateful, and gratitude is itself a strong predictor of SWB (Frost et al., 2007). Additionally, those who think that possessions are a sign of success tend to have a negative self-image (Frost et al., 2007), a common source of unhappiness. These findings complement Brown and Kasser's (2005) observations in the study mentioned above. They found that the relationship between environmentalism and SWB is mediated by the adoption of 
'intrinsic values' (Brown \& Kasser, 2005, p. 361)—e.g., personal growth and achievement, and close social relationships (as opposed to 'extrinsic values' like physical appearance, social status, or prestige). The satisfaction of intrinsic values does not typically require much in the way of material resources. Thus, people who pursue these goals consume less and engage in more PEBs (Unanue et al., 2016). In fact, an orientation towards intrinsic values is actually a much stronger predicter of PEB than pro-environmental values (Unanue et al., 2016). As Brown and Kasser write, "people holding more intrinsic values are unlikely to be very interested in large "trophy" homes or gas-guzzling vehicles that often reflect ostentatious displays of wealth or image enhancement' (2005, p. 361). Things like personal growth and close relationships are wellknown contributors to SWB (Baumeister \& Leary, 1995; Mehl et al., 2010; Nelson et al., 2016; Ryff, 1989; Ryff \& Keyes, 1995) — as well as physical health (Cohen, 2004; Holt-Lunstad et al., 2010).

Self-determination theory, a prominent explanation for variation in SWB, posits that people have three main psychological needs: competence, autonomy, and relatedness (Ryan \& Deci, 2000). To be happy, in other words, people need to feel: (1) capable, and able to handle life's challenges; (2) free to make their own decisions; and (3) that they belong, and have good relationships (Ryan et al., 2013). Many PEBs directly or indirectly contribute to the satisfaction of these needs (Kasser, 2009). For instance, finding new uses for old items or ways of improving one's energy efficiency can make one feel particularly competent. ${ }^{8}$ Taking control of one's consumption and spending promotes a sense of autonomy (Boujbel \& d'Astous, 2012).

\footnotetext{
${ }^{8}$ They can also just be fun, like solving a puzzle. This is an instance of the 'hedonic benefits of thrift' (Chancellor \& Lyubomirsky, 2014).
} 
Frugality—defined as "behaviour geared towards the voluntary restriction of consumption and the resourceful use of available resources'- has been found to predict both a greater sense of autonomy and improved relationship quality (Muiños et al., 2015). Living with others, which reduces one's ecological footprint, also leads to improved social support, which is enormously important for all aspects of well-being. For instance, lack of social integration is as detrimental to one's physical health as smoking and obesity (Holt-Lunstad et al., 2010). Now, obviously there are also ecologically unfriendly ways of satisfying these same needs. But a green lifestyle naturally includes a lot of higher need satisfaction, thus making it an effective route to happiness - and one which is likely to be far more accessible to most people than less environmentally friendly alternatives.

Under conditions of scarcity, more is better. But for those living in conditions of abundance, such as contemporary developed economies, more is often worse —not just for our planet, but for ourselves. More food often means worse health; more square-footage means more rent or mortgage, and more cleaning; and more gadgets mean more frenetic distractions (Naish, 2008). When we buy new things, we quickly adapt to them and lose interest through a process called 'hedonic adaptation' (Lyubomirsky, 2012). Humans have an incredible ability to adapt to their circumstances. Thus, higher rates of consumption (above subsistence level) fail to make lasting contributions to people's happiness because people quickly adapt to them. Indeed, because we adapt so quickly to both good and bad things, we can expect that, even if some lifestyle changes feel like losses at first (e.g., it's less convenient to ride the bus than drive), it won't affect one for long. In other words, we can expect hedonic adaptation to absorb negative effects of reduced consumption. 
In summary, there is strong evidence that environmentally friendly lifestyles do not commonly involve sacrifices to (i.e., net negative effects on) happiness and well-being. Rather, they typically come with greater well-being. This is true for many or most people, not just environmentalists living in rich countries. (Though now that the positive SWB-PEB relationship has been established, future research might productively focus on who benefits the most from which PEBs under what conditions, etc.) Once one's basic physical needs are met, the things with the biggest impact on happiness-e.g., close relationships, personal growth, a sense of purpose-don't require a significant ecological footprint. Indeed, the overconsumption of resources can easily get in the way of satisfying these higher needs. Thus, the suggestion that going green is bad for you is not only counterproductive rhetoric, it's false.

\section{Voluntary simplicity}

The voluntary simplicity movement nicely illustrates the kind of rhetoric I'm recommending environmentalists adopt. Voluntary simplifiers are people who choose to work and consume less, and to do both more thoughtfully (Alexander, 2011; Elgin, 2010; Gambrel \& Cafaro, 2010). There are a number of very similar movements going by other names, including: minimalism (Millburn \& Nicodemus, 2014), enoughism (Naish, 2008), and 'downsizing' or 'downshifting' (Juniu, 2000). Indeed, the basic premise of living simply has been around for almost all of historical time, and has figured prominently in practically every religious and spiritual tradition (Vanenbroeck, 1991; Xenos, 2017).

As with all social movements, there is incredible variety in the forms that voluntary simplicity takes, and in the motivations behind it. According to a multi-national survey of simplifiers, motivations range from decluttering to living mindfully/spiritually to making time for oneself and one's family (Alexander \& Ussher, 2012). The most commonly cited motivation 
(mentioned by over $80 \%$ of respondents) was 'environmental concern'. However, the movement is not primarily an environmentalist one. ${ }^{9}$ It's driven by a rejection of consumer culture and a concern for personal well-being. Here are some representative statements:

[The lifestyle] involves... minimizing expenditure on consumer goods and services, and directing progressively more time and energy towards pursuing nonmaterialistic sources of satisfaction and meaning. This generally means accepting a lower income and a lower level of consumption, in exchange for more time and freedom to pursue other life goals, such as community or social engagements, more time with family, artistic or intellectual projects, more fulfilling employment, political participation, sustainable living, spiritual exploration, reading, contemplation, relaxation, pleasure-seeking, love, and so on... (Alexander, 2011, p. 2)

It's a way to escape the excesses of the world around us - the excesses of consumerism, material possessions, clutter, having too much to do, too much debt, too many distractions, too much noise. But too little meaning. [This] is a way of eschewing the non-essential in order to focus on what's truly important, what gives our lives meaning, what gives us joy and value. (Babauta, n.d.)

${ }^{9}$ Juliet Schor (1992), who might be seen as the social scientist representative of this movement hardly discusses environmental motivations for cutting back on work and consumption. Thus, her writings may exemplify the kind of message that will be most compelling for conservatives and climate deniers (see note 3 ). 
As these quotes illustrate, voluntary simplifiers not only deny that there is a conflict between well-being and reduced consumption, they take reduced consumption to be an effective means to well-being.

A number of empirical studies have confirmed that voluntary simplifiers have a smaller ecological impact, and are indeed happier than non-simplifiers (Boujbel \& d'Astous, 2012; Brown \& Kasser, 2005; Kennedy et al., 2013; Rich et al., 2017). While these are correlational data, which don't license causal conclusions, there are longitudinal data showing that those who adopt a lifestyle of reduced consumption are subsequently happier. In a study looking at 2,268 simplifiers from around the world (concentrated in North America), fully 87\% said that they were happier (with almost half of respondents reporting being 'much happier') as a result of simplifying their lives (Alexander \& Ussher, 2012). While this is a self-selected sample, this goes some way towards establishing a causal relationship.

Given the diversity within the movement, there are many explanations for why voluntary simplicity might promote well-being. The focus on non-material values and higher psychological needs is an obvious route from simplicity to well-being (Kasser, 2009). Indeed, Rich and colleagues (2017) found that the relationship between a simple lifestyle and SWB was mediated by the satisfaction of the needs for autonomy, competence, and relatedness. Another route is financial (Alexander \& Ussher, 2012, p. 76). American households collectively bear over $\$ 13$ trillion in debt (Federal Reserve Bank, 2018). Even excluding home mortgages, the figure is almost $\$ 4$ trillion. For many, borrowing is the only way to sustain the lavish consumption promoted by the advertising industry and consumer culture. Debt is, naturally, a major source of stress and anxiety. Since reduced consumption means reduced spending, becoming a simplifier can get one out of debt and moving towards financial freedom. 
Reduced spending also means that simplifiers can work less, which will tend to make them happier. The average number of work-hours per week has nearly doubled since the 1970's (Bunting, 2004; Kuhn \& Lozano, 2008; Schor, 1992). For many people, working long hours means lower SWB (Bonebright et al., 2000; Rich et al., 2017). And, given that material goods affect happiness so much less than experiences (Gilovich et al., 2015), the things one can buy with the extra money are less impactful than the experiences one gives up by working more. 'Time affluence', the feeling of having plenty of time and not being rushed, is positively associated with SWB (Hershfield et al., 2016; Kasser \& Sheldon, 2009; Whillans et al., 2016). This is unsurprising as time pressure is a common source of stress, and people tend to spend their free time doing things they enjoy or consider meaningful. Moreover, time affluence, unlike monetary affluence, doesn't come with (rapidly) diminishing marginal value. The wealth-SWB relationship is curvilinear and asymptotic (Diener \& Seligman, 2004). The time affluence-SWB relationship, on the other hand, is linear. Since consuming less gives one the freedom to work less, simplifiers have (at least the option of) greater time affluence. And, given their emphasis on pursuing meaningful activities, they are likely to spend that time in beneficial ways.

\section{Conclusion}

We live at a crucial moment in human history. We know beyond reasonable doubt that human activity is damaging our planet. Yet, we don't act like we care. I argued that this is due partly to the counterproductive way in which green lifestyles are framed as sacrifices. But we can fix this problem. The message that consuming more very likely won't make you better off, and that people are generally happier living eco-friendly lifestyles may be one of our most powerful tools. Let's abandon the rhetoric of self-sacrifice, which is both unhelpful and untrue. Instead, spread the word: going green is good for you! 


\section{References}

Agar, N. (2016, July 31). Why techno-optimism is dangerous. HuffPost. https://www.huffpost.com/entry/technooptimism-dangerous_b_7746682

Ainslie, G. (2001). Breakdown of Will. Cambridge University Press.

Alexander, S. (2011). The voluntary simplicity movement: Reimagining the good life beyond consumer culture. SSRN Electronic Journal. https://doi.org/10.2139/ssrn.1970056

Alexander, S. (2014). A critique of techno-optimism: Efficiency without sufficiency is lost [Working Paper]. Melbourne Sustainable Society Institute.

http://www.magnusjohnston.ca/uploads/8/4/9/4/84946882/alexander_-_critique_of_techno_optimism.pdf

Alexander, S., \& Ussher, S. (2012). The voluntary simplicity movement: A multi-national survey analysis in theoretical context. Journal of Consumer Culture, 12(1), 66-86. https://doi.org/10.1177/1469540512444019

Babauta, L. (n.d.). Minimalist FAQs. Mnmlist. Retrieved July 31, 2018, from http://mnmlist.com/minimalist-faqs/

Bain, P. G., Hornsey, M. J., Bongiorno, R., \& Jeffries, C. (2012). Promoting pro-environmental action in climate change deniers. Nature Climate Change, 2(8), 600-603. https://doi.org/10.1038/nclimate1532

Bain, P. G., Milfont, T. L., Kashima, Y., Bilewicz, M., Doron, G., Garðarsdóttir, R. B., Gouveia, V. V., Guan, Y., Johansson, L.-O., Pasquali, C., Corral-Verdugo, V., Aragones, J. I., Utsugi, A., Demarque, C., Otto, S., Park, J., Soland, M., Steg, L., González, R., ... Saviolidis, N. M. (2016). Co-benefits of addressing climate change can motivate action around the world. Nature Climate Change, 6(2), 154-157. https://doi.org/10.1038/nclimate2814

Bauer, M. A., Wilkie, J. E. B., Kim, J. K., \& Bodenhausen, G. V. (2012). Cuing consumerism: Situational materialism undermines personal and social well-being. Psychological Science, 23(5), 517-523. https://doi.org/10.1177/0956797611429579

Baumeister, R. F. (2001). Bad is stronger than good. Review of General Psychology, 5(4), 323-370.

Baumeister, R. F., \& Leary, M. R. (1995). The need to belong: Desire for interpersonal attachments as a fundamental human motivation. Psychological Bulletin, 117, 497-529.

Bilandzic, H., Kalch, A., \& Soentgen, J. (2017). Effects of goal framing and emotions on perceived threat and willingness to sacrifice for climate change. Science Communication, 39(4), 466-491. https://doi.org/10.1177/1075547017718553

Bliuc, A.-M., McGarty, C., Thomas, E. F., Lala, G., Berndsen, M., \& Misajon, R. (2015). Public division about climate change rooted in conflicting socio-political identities. Nature Climate Change, 5(3), 226-229. https://doi.org/10.1038/nclimate2507

Bonebright, C. A., Clay, D. L., \& Ankenmann, R. D. (2000). The relationship of workaholism with work-life conflict, life satisfaction, and purpose in life. 47(4), 469-477.

Boujbel, L., \& d'Astous, A. (2012). Voluntary simplicity and life satisfaction: Exploring the mediating role of consumption desires. Journal of Consumer Behaviour, 11(6), 487-494. https://doi.org/10.1002/cb.1399

Broome, J. (2012). Climate Matters: Ethics in a Warming World. W. W. Norton and Company.

Brown, K. W., \& Kasser, T. (2005). Are psychological and ecological well-being compatible? The role of values, mindfulness, and lifestyle. Social Indicators Research, 74(2), 349-368.

Bunting, M. (2004). Willing Slaves: How the Overwork Culture Is Ruling Our Lives. HarperCollins.

Chancellor, J., \& Lyubomirsky, S. (2014). Money for happiness: The hedonic benefits of thrift. Consumption and Well-Being in the Material World, 13-47. https://doi.org/10.1007/978-94-007-7368-4_2

Cohen, S. (2004). Social relationships and health. American Psychologist, 59(8), 676. 
Corral-Verdugo, V., Montiel-Carbajal, M. M., Sotomayor-Petterson, M., Frías-Armenta, M., Tapia-Fonllem, C., \& Fraijo-Sing, B. (2011). Psychological wellbeing as correlate of sustainable behaviors. International Journal of Hispanic Psychology; Hauppauge, 4(1), 31-44.

De Young, R. (1990). Some psychological aspects of living lightly: Desired lifestyle patterns and conservation behavior. Journal of Environtal Systems, 20(3), 215-227.

De Young, R. (2000). Expanding and evaluating motives for environmentally responsible behavior. Journal of Social Issues, 56(3), 509-526.

Diener, E. (2012). New findings and future directions for subjective well-being research. American Psychologist, 67(8), 590-597. https://doi.org/10.1037/a0029541

Diener, E., Lucas, R. E., \& Oishi, S. (2002). Subjective well-being: The science of happiness and life satisfaction. In C. Snyder, R. Lopez, \& J. Shane (Eds.), Handbook of Positive Psychology (pp. 63-73). Oxford University Press.

Diener, E., \& Seligman, M. E. P. (2004). Beyond money: Toward an economy of well-being. Psychological Science in the Public Interest, 5(1), 1-31.

Dietz, T., Gardner, G. T., Gilligan, J., Stern, P. C., \& Vandenbergh, M. P. (2009). Household actions can provide a behavioral wedge to rapidly reduce US carbon emissions. Proceedings of the National Academy of Sciences, 106(44), 18452-18456. https://doi.org/10.1073/pnas.0908738106

Dittmar, H., Bond, R., Hurst, M., \& Kasser, T. (2014). The relationship between materialism and personal wellbeing: A meta-analysis. Journal of Personality and Social Psychology, 107(5), 879-924. https://doi.org/10.1037/a0037409

Does, S., Derks, B., \& Ellemers, N. (2011). Thou shalt not discriminate: How emphasizing moral ideals rather than obligations increases Whites' support for social equality. Journal of Experimental Social Psychology, 47(3), 562-571. https://doi.org/10.1016/j.jesp.2010.12.024

Elgin, D. (2010). Voluntary Simplicity (2nd ed.). Harper.

Elliott, K. C. (2014). Anthropocentric indirect arguments for environmental protection. Ethics, Policy \& Environment, 17(3), 243-260. https://doi.org/10.1080/21550085.2014.955311

Federal Reserve Bank. (2018). Quarterly report on household debt and credit. Center for Microeconomic Data. https://www.newyorkfed.org/medialibrary/interactives/householdcredit/data/pdf/HHDC_2018Q1.pdf

Feinberg, M., \& Willer, R. (2011). Apocalypse soon? Dire messages reduce belief in global warming by contradicting just-world beliefs. Psychological Science, 22(1), 34-38. https://doi.org/10.1177/0956797610391911

Frost, R. O., Kyrios, M., McCarthy, K. D., \& Matthews, Y. (2007). Self-ambivalence and attachment to possessions. Journal of Cognitive Psychotherapy; New York, 21(3), 232-242.

Fujii, S., \& Kitamura, R. (2003). What does a one-month free bus ticket do to habitual drivers? An experimental analysis of habit and attitude change. Transportation, 30(1), 81-95. https://doi.org/10.1023/A:1021234607980

Gambrel, J. C., \& Cafaro, P. (2010). The virtue of simplicity. Journal of Agricultural and Environmental Ethics, 23(1-2), 85-108. https://doi.org/10.1007/s10806-009-9187-0

Gardener, G., \& Stern, P. (2009). The short list: The most effective actions U.S. households can take to curb climate change. Environment Magazine. https://www.tandfonline.com/doi/abs/10.3200/ENVT.50.5.12-25

Gardiner, S. (2006). A perfect moral storm: Climate change, intergenerational ethics and the problem of moral corruption. Environmental Values, 15(3), 397-413.

Gardner, G. T., \& Stern, P. C. (2002). Environmental Problems and Human Behavior (2nd ed.). Pearson Custom Publishing.

Gifford, R., \& Nilsson, A. (2014). Personal and social factors that influence pro-environmental concern and behaviour: A review. International Journal of Psychology, 49, 141-157. 
Gilovich, T., Kumar, A., \& Jampol, L. (2015). A wonderful life: Experiential consumption and the pursuit of happiness. Journal of Consumer Psychology, 25(1), 152-165. https://doi.org/10.1016/j.jcps.2014.08.004

Haidt, J. (2012). The Righteous Mind: Why Good People are Divided by Politics and Religion. Pantheon Books.

Henrich, J., Heine, S., \& Norenzayan, A. (2010). The weirdest people in the world? Behavioral and Brain Sciences, $33(2), 61-83$.

Hershfield, H. E., Mogilner, C., \& Barnea, U. (2016). People who choose time over money are happier. Social Psychological and Personality Science, 7(7), 697-706. https://doi.org/10.1177/1948550616649239

Hertwich, E. G. (2005). Life cycle approaches to sustainable consumption: A critical review. Environmental Science and Technology, 39, 4673-4684.

Hertwich, E. G., \& Peters, G. P. (2009). Carbon footprint of nations: A global, trade-linked analysis. Environmental Science and Technology, 43, 6414-6420.

Hoffman, A. J. (2011). Talking past each other? Cultural framing of skeptical and convinced logics in the climate change debate. Organization \& Environment, 24(1), 3-33. https://doi.org/10.1177/1086026611404336

Holt-Lunstad, J., Smith, T. B., \& Layton, J. B. (2010). Social relationships and mortality risk: A meta-analytic review. PLoS Medicine, 7(7), 1-20.

Hornsey, M. J., Harris, E. A., Bain, P. G., \& Fielding, K. S. (2016). Meta-analyses of the determinants and outcomes of belief in climate change. Nature Climate Change, 6(6), 622-626. https://doi.org/10.1038/nclimate2943

Hurst, M., Dittmar, H., Bond, R., \& Kasser, T. (2013). The relationship between materialistic values and environmental attitudes and behaviors: A meta-analysis. Journal of Environmental Psychology, 36, $257-$ 269. https://doi.org/10.1016/j.jenvp.2013.09.003

IPCC. (2007). Climate Change 2007: Synthesis Report. Intergovernmental Panel on Climate Change.

Jackson, T. (2008). Live better by consuming less?: Is there a "double dividend" in sustainable consumption? Journal of Industrial Ecology, 9(1-2), 19-36. https://doi.org/10.1162/1088198054084734

Jacob, J., Jovic, E., \& Brinkerhoff, M. B. (2009). Personal and planetary well-being: Mindfulness meditation, proenvironmental behavior and personal quality of life in a survey from the social justice and ecological sustainability movement. Social Indicators Research, 93(2), 275-294. https://doi.org/10.1007/s11205-0089308-6

Jones, C., Hine, D. W., \& Marks, A. D. G. (2017). The future is now: Reducing psychological distance to increase public engagement with climate change. Risk Analysis, 37(2), 331-341. https://doi.org/10.1111/risa.12601

Juniu, S. (2000). Downshifting: Regaining the essence of leisure. Journal of Leisure Research, 32(1), 69-73. https://doi.org/10.1080/00222216.2000.11949888

Kahan, D. (2010). Fixing the communications failure. Nature, 463, 296-297. https://doi.org/10.1038/463296a

Kahneman, D. (2011). Thinking, Fast and Slow. Doubleday Canada.

Kahneman, D., Knetsch, J. L., \& Thaler, R. H. (1991). Anomalies: The endowment effect, loss aversion, and status quo bias. Journal of Economic Perspectives, 5(1), 193-206. https://doi.org/10.1257/jep.5.1.193

Kaida, N., \& Kaida, K. (2016). Pro-environmental behavior correlates with present and future subjective well-being. Environment, Development and Sustainability, 18(1), 111-127. https://doi.org/10.1007/s10668-015-9629-y

Karp, D. G. (1996). Values and their effect on environmental behavior. Environment and Behavior, 28(1), 111-133.

Kasser, T. (2002). The High Price of Materialism. MIT Press.

Kasser, T. (2009). Psychological need satisfaction, personal well-being, and ecological sustainability. Ecopsychology, 1(4), 175-180. https://doi.org/10.1089/eco.2009.0025

Kasser, T. (2017). Living both well and sustainably: A review of the literature, with some reflections on future research, interventions and policy. Philosophical Transactions of the Royal Society A: Mathematical, Physical and Engineering Sciences, 375, 1-13. https://doi.org/10.1098/rsta.2016.0369 
Kasser, T., \& Ahuvia, A. (2002). Materialistic values and well-being in business students. European Journal of Social Psychology, 32(1), 137-146. https://doi.org/10.1002/ejsp.85

Kasser, T., Rosenblum, K. L., Sameroff, A. J., Deci, E. L., Niemiec, C. P., Ryan, R. M., Árnadóttir, O., Bond, R., Dittmar, H., Dungan, N., \& Hawks, S. (2014). Changes in materialism, changes in psychological wellbeing: Evidence from three longitudinal studies and an intervention experiment. Motivation and Emotion, 38(1), 1-22. https://doi.org/10.1007/s11031-013-9371-4

Kasser, T., \& Ryan, R. M. (1993). A dark side of the American dream: Correlates of financial success as a central life aspiration. Journal of Personality and Social Psychology, 65(2), 410-422. https://doi.org/10.1037/0022-3514.65.2.410

Kasser, T., \& Sheldon, K. M. (2009). Time affluence as a path toward personal happiness and ethical business practice: Empirical evidence from four studies. Journal of Business Ethics, 84, 243-255.

Kennedy, E. H., Krahn, H., \& Krogman, N. T. (2013). Downshifting: An exploration of motivations, quality of life, and environmental practices. Sociological Forum, 28(4), 764-783. https://doi.org/10.1111/socf.12057

Klöckner, C. A. (2013). A comprehensive model of the psychology of environmental behaviour-A meta-analysis. Global Environmental Change, 23(5), 1028-1038. https://doi.org/10.1016/j.gloenvcha.2013.05.014

Kuhn, P., \& Lozano, F. (2008). The expanding workweek? Understanding trends in long work hours among U.S. men, 1979-2006. Journal of Labor Economics, 26(2), 311-343.

Lawlor, R. (2016). The absurdity of economists' sacrifice-free solutions to climate change. Ethics, Policy \& Environment, 19(3), 350-365. https://doi.org/10.1080/21550085.2016.1226239

Lee, P. S., Sung, Y. H., Wu, C. C., Ho, L. C., \& Chiou, W. B. (2018). Using episodic future thinking to preexperience climate change increases pro-environmental behavior. Environment and Behavior, 1-22. https://doi.org/10.1177\%2F0013916518790590

Leiserowitz, A., Maibach, E., Roser-Renouf, C., Rosenthal, S., Cutler, M., \& Kotcher, J. (2018). Climate change in the American mind. Yale University and George Mason University. http://climatecommunication.yale.edu/wp-content/uploads/2018/04/Climate-Change-American-MindMarch-2018-1.pdf

Lewandowsky, S., \& Oberauer, K. (2016). Motivated rejection of science. Current Directions in Psychological Science, 25(4), 217-222.

Liberman, N., Trope, Y., \& Stephan, E. (2007). Psychological distance. In A. Kruglanski \& T. Higgins (Eds.), Social Psychology: Handbook of Basic Principles (Vol. 2, pp. 353-383). Guilford Press.

Lindenberg, S., \& Steg, L. (2007). Normative, gain and hedonic goal frames guiding environmental behavior. Journal of Social Issues, 63(1), 117-137. https://doi.org/10.1111/j.1540-4560.2007.00499.x

Lyubomirsky, S. (2012). Hedonic adaptation to positive and negative experiences. In S. Folkman (Ed.), The Oxford Handbook of Stress, Health, and Coping (pp. 200-224).

Maibach, E. W., Nisbet, M., Baldwin, P., Akerlof, K., \& Diao, G. (2010). Reframing climate change as a public health issue: An exploratory study of public reactions. 11.

McDonald, R. I., Chai, H. Y., \& Newell, B. R. (2015). Personal experience and the 'psychological distance' of climate change: An integrative review. Journal of Environmental Psychology, 44, 109-118. https://doi.org/10.1016/j.jenvp.2015.10.003

Mehl, M. R., Vazire, S., Holleran, S. E., \& Clark, C. S. (2010). Eavesdropping on happiness: Well-being is related to having less small talk and more substantive conversations. Psychological Science, 21(4), 539-541. https://doi.org/10.1177/0956797610362675

Millburn, J. F., \& Nicodemus, R. (2014, June 7). Minimalism: An elevator pitch. The Minimalists. https://www.theminimalists.com/pitch/ 
Morton, T. A., Rabinovich, A., Marshall, D., \& Bretschneider, P. (2011). The future that may (or may not) come: How framing changes responses to uncertainty in climate change communications. Global Environmental Change, 21(1), 103-109. https://doi.org/10.1016/j.gloenvcha.2010.09.013

Moser, S., \& Dilling, L. (2011). Communicating climate change: Closing the science-action gap. In The Oxford Handbook of Climate Change and Society (pp. 161-174). Oxford University Press.

Muiños, G., Suárez, E., Hess, S., \& Hernández, B. (2015). Frugality and psychological wellbeing: The role of voluntary restriction and the resourceful use of resources. Psyecology, 6(2), 169-190. https://doi.org/10.1080/21711976.2015.1026083

Naish, J. (2008). Enough: Breaking Free from the World of More. Hodder \& Stoughton.

National Geographic. (2014). Greendex 2014: Consumer choice and the environment - a worldwide tracking survey. National Geographic. https://images.nationalgeographic.com/wpf/ mediacontent/file/NGS_2014_Greendex_Highlights_FINAL-cb1411689730.pdf

Nelson, S. K., Layous, K., Cole, S. W., \& Lyubomirsky, S. (2016). Do unto others or treat yourself? The effects of prosocial and self-focused behavior on psychological flourishing. Emotion, 16(6), 850-861. https://doi.org/10.1037/emo0000178

Newell, B. R., McDonald, R. I., Brewer, M., \& Hayes, B. K. (2014). The psychology of environmental decisions. Annual Review of Environment and Resources, 39(1), 443-467. https://doi.org/10.1146/annurev-environ010713-094623

Newell, B. R., \& Pitman, A. J. (2010). The psychology of global warming: Improving the fit between the science and the message. Bulletin of the American Meteorological Society, 91(8), 1003-1014. https://doi.org/10.1175/2010BAMS2957.1

O'Neill, S., \& Nicholson-Cole, S. (2009). "Fear won't do it": Promoting positive engagement with climate change through visual and iconic representations. Science Communication, 30(3), 355-379. https://doi.org/10.1177/1075547008329201

Pahl, S., \& Bauer, J. (2013). Overcoming the distance: Perspective taking with future humans improves environmental engagement. Environment and Behavior, 45(2), 155-169. https://doi.org/10.1177/0013916511417618

Peter, L., Diane, L., Marc, A., David, F., Betty, F., \& McGrath, J. E. (1972). Bystander effect in a demand-withoutthreat situation. Journal of Personality and Social Psychology, 24(2), 166-171. https://doi.org/10.1037/h0033380

Rich, S. A., Hanna, S., \& Wright, B. J. (2017). Simply satisfied: The role of psychological need satisfaction in the life satisfaction of voluntary simplifiers. Journal of Happiness Studies, 18(1), 89-105. https://doi.org/10.1007/s10902-016-9718-0

Richins, M. L., \& Dawson, S. (1992). A consumer values orientation for materialism and its measurement: Scale development and validation. Journal of Consumer Research, 19(3), 303-316. https://doi.org/10.1086/209304

Ritchie, H. (2018, October 16). Global inequalities in $\mathrm{CO}_{2}$ emissions. Our World in Data. https://ourworldindata.org/co2-by-income-region

Rottenstreich, Y., \& Hsee, C. K. (2001). Money, kisses, and electric shocks: On the affective psychology of risk. Psychological Science, 12(3), 185-190.

Ryan, R. M., Curren, R. R., \& Deci, E. L. (2013). What humans need: Flourishing in Aristotelian philosophy and self-determination theory. In A. S. Waterman (Ed.), The Best Within Us: Positive Psychology Perspectives on Eudaimonia (pp. 57-75). American Psychological Association.

Ryan, R. M., \& Deci, E. L. (2000). Self-determination theory and the facilitation of intrinsic motivation, social development, and well-being. American Psychologist, 55(1), 68-78.

Ryff, C. D. (1989). Happiness is everything, or is it? Explorations on the meaning of psychological well-being. Journal of Personality and Social Psychology, 57(6), 1069-1081. 
Ryff, C. D., \& Keyes, C. L. M. (1995). The structure of psychological well-being revisited. Journal of Personality and Social Psychology, 69(4), 719-727.

Scannell, L., \& Gifford, R. (2013). Personally relevant climate change: The role of place attachment and local versus global message framing in engagement. Environment and Behavior, 45(1), 60-85. https://doi.org/10.1177/0013916511421196

Schmitt, M. T., Aknin, L. B., Axsen, J., \& Shwom, R. L. (2018). Unpacking the relationships between proenvironmental behavior, life satisfaction, and perceived ecological threat. Ecological Economics, 143, 130140. https://doi.org/10.1016/j.ecolecon.2017.07.007

Schor, J. (1992). The Overworked American: The Unexpected Decline Of Leisure. Basic Books.

Shellenberger, M., \& Nordhaus, T. (2011). Evolve. Orion Magazine. https://orionmagazine.org/article/evolve/

Soliman, M., Alisat, S., Bashir, N. Y., \& Wilson, A. E. (2018). Wrinkles in time and drops in the bucket: Circumventing temporal and social barriers to pro-environmental behavior. SAGE Open, 1-10. https://doi.org/10.1177/2158244018774826

Spence, A., Poortinga, W., \& Pidgeon, N. (2012). The psychological distance of climate change. Risk Analysis, 32(6), 957-972. https://doi.org/10.1111/j.1539-6924.2011.01695.x

Steg, L., Bolderdijk, J. W., Keizer, K., \& Perlaviciute, G. (2014). An integrated framework for encouraging proenvironmental behaviour: The role of values, situational factors and goals. Journal of Environmental Psychology, 38, 104-115. https://doi.org/10.1016/j.jenvp.2014.01.002

Steg, L., \& Vlek, C. (2009). Encouraging pro-environmental behaviour: An integrative review and research agenda. Journal of Environmental Psychology, 29(3), 309-317. https://doi.org/10.1016/j.jenvp.2008.10.004

Sunstein, C. R., \& Thaler, R. (2008). Nudge: The Politics of Libertarian Paternalism. New Haven.

Thurston, G. D. (2013). Mitigation policy: Health co-benefits. Nature Climate Change, 3(10), 863-864. https://doi.org/10.1038/nclimate2013

Tobler, C., Visschers, V. H. M., \& Siegrist, M. (2012). Addressing climate change: Determinants of consumers' willingness to act and to support policy measures. Journal of Environmental Psychology, 32(3), 197-207. https://doi.org/10.1016/j.jenvp.2012.02.001

Trope, Y., \& Liberman, N. (2010). Construal-Level Theory of Psychological Distance. Psychological Review, 117(2), 440-463. https://doi.org/10.1037/a0018963

Tsang, J.-A., Carpenter, T. P., Roberts, J. A., Frisch, M. B., \& Carlisle, R. D. (2014). Why are materialists less happy? The role of gratitude and need satisfaction in the relationship between materialism and life satisfaction. Personality and Individual Differences, 64, 62-66. https://doi.org/10.1016/j.paid.2014.02.009

Tversky, A., \& Kahneman, D. (1981). The framing of decisions and the psychology of choice. Science, 211(4481), 453-458. https://doi.org/10.1126/science.7455683

Unanue, W., Vignoles, V. L., Dittmar, H., \& Vansteenkiste, M. (2016). Life goals predict environmental behavior: Cross-cultural and longitudinal evidence. Journal of Environmental Psychology, 46, 10-22. https://doi.org/10.1016/j.jenvp.2016.02.001

Vandenbergh, M., Stern, P., Gardner, G., Dietz, T., \& Gilligan, J. (2010). Implementing the behavioral wedge: Designing and adopting effective carbon emissions reduction programs. Environmental Law Reporter, 40, 10547-10554.

Vanenbroeck, G. (Ed.). (1991). Less is More: An Anthology of Ancient and Modern Voices Raised in Praise of Simplicity.

Vansteenkiste, M., Duriez, B., Simons, J., \& Soenens, B. (2006). Materialistic Values and Well-Being Among Business Students: Further Evidence of Their Detrimental Effect1. Journal of Applied Social Psychology, 36(12), 2892-2908. https://doi.org/10.1111/j.0021-9029.2006.00134.x 
Walker, B. J. A., Kurz, T., \& Russel, D. (2018). Towards an understanding of when non-climate frames can generate public support for climate change policy. Environment and Behavior, 50(7), 781-806. https://doi.org/10.1177/0013916517713299

Wang, S., Hurlstone, M. J., Leviston, Z., Walker, I., \& Lawrence, C. (2019). Climate Change From a Distance: An Analysis of Construal Level and Psychological Distance From Climate Change. Frontiers in Psychology, 10. https://doi.org/10.3389/fpsyg.2019.00230

Wapner, P. (2010). Sacrifice in an age of comfort. In M. Maniates \& J. Meyer (Eds.), The Environmental Politics of Sacrifice. MIT Press.

Welsch, H., \& Kühling, J. (2010). Pro-environmental behavior and rational consumer choice: Evidence from surveys of life satisfaction. Journal of Economic Psychology, 31, 405-420.

Welsch, H., \& Kühling, J. (2011). Are pro-environmental consumption choices utility-maximizing? Evidence from subjective well-being data. Ecological Economics, 72, 75-87. https://doi.org/10.1016/j.ecolecon.2011.04.015

Welsch, H., \& Kühling, J. (2018). How green self image is related to subjective well-being: Pro-environmental values as a social norm. Ecological Economics, 149, 105-119. https://doi.org/10.1016/j.ecolecon.2018.03.002

West, J. J., Smith, S. J., Silva, R. A., Naik, V., Zhang, Y., Adelman, Z., Fry, M. M., Anenberg, S., Horowitz, L. W., \& Lamarque, J.-F. (2013). Co-benefits of mitigating global greenhouse gas emissions for future air quality and human health. Nature Climate Change, 3(10), 885-889. https://doi.org/10.1038/nclimate2009

Whillans, A. V., Weidman, A. C., \& Dunn, E. W. (2016). Valuing time over money is associated with greater happiness. Social Psychological and Personality Science, 7(3), 213-222. https://doi.org/10.1177/1948550615623842

Whitmarsh, L. (2011). Scepticism and uncertainty about climate change: Dimensions, determinants and change over time. Global Environmental Change, 21(2), 690-700. https://doi.org/10.1016/j.gloenvcha.2011.01.016

Wright, N., \& Larsen, V. (1993). Materialism and life satisfaction: A meta-analysis. Journal of Consumer Satisfaction, Dissatisfaction, and Complaining Behavior, 6(1), 5.

Xenos, N. (2017). The austere life. Philosophical Transactions of the Royal Society A: Mathematical, Physical and Engineering Sciences, 375(2095), 20160378. https://doi.org/10.1098/rsta.2016.0378

Xiao, J. J., \& Li, H. (2011). Sustainable consumption and life satisfaction. Social Indicators Research, 104(2), 323329. https://doi.org/10.1007/s11205-010-9746-9 